Original Research

\title{
Content Validity and the Reliability of Technological Competency as Caring in The Nursing Instrument_Indonesian Version (TCCNI_IV)
}

\author{
Ignata Yuliati, Ni Luh Agustini Purnama and Sri Winarni
}

Institute of Health Science Katolik St Vincentius a Paulo, Surabaya, Indonesia

\begin{abstract}
Introduction: The TCCNI has not been used to conduct a study in Indonesia previously. The researcher has thus conducted a study on technological competency as a caring in nursing instrument Indonesian version (TCCNI_IV). This study aims to examine the content validity and reliability of the TCCNI_IV.
\end{abstract}

Methods: An exploratory sequential mixed method research design was used in this study. The researcher used closed-ended question asked of five (5) experts on the content of TCCNI-IV. The researcher explored the expert's opinion about each statement of TCCNI_IV, and they required suggestions for the statements that were not relevant. Furthermore, the researcher analyzed and rewrote the statements according to the expert's input. There are twenty-five (25) items in the TCCNI_IV involving technological knowledge and technological caring as an expression of caring in the nursing dimension. Furthermore, the researcher used the TCCNI_IV to gain quantitative data from the 135 nurses in the nursing wards of the hospitals. Based on a finite population of 208 nurses, a total of 135 samples (nurses) participated in the quantitative study. The selection of the participants was through simple random sampling. There were 135 nurses from the nursing wards in the hospitals $(n=135)$ with experience of at least 1 year in nursing practice. The item content validity (I-CVI) and scale content validity (S-CVI) was tested. The reliability was determined using Cronbach's alpha $\alpha$.

Results: The "item content validity of the TCCNI_IV ratings ranged from .60 to 1.0. The scale content validity index (S-CVI) was 0.936 . The Cronbach's alpha coefficient of .980 indicates there to be good reliability.

Conclusion: The technological competency as a caring in nursing instrument Indonesian version (TCCNIIIV) is thus found to be valid and reliable. It is recommended that the developed instrument needs to be further tested for its reliability and validity in a larger setting.

\section{ARTICLE HISTORY}

Received: December 25, 2018

Accepted: January 10, 2020

\section{KEYWORDS}

instrument development validation; technological competency; tccni_iv.

\section{CONTACT}

Ignata Yuliati

$\triangle$ ignatayuli@gmail.com

$\equiv$ Institute of Health Science Katolik St Vincentius a Paulo, Surabaya, Indonesia

Cite this as: Yuliati, I., Purnama, N.L.A., \& Winarni, S. (2019). Content Validity and the Reliability of Technological Competency as Caring in The Nursing Instrument_Indonesian Version (TCCNI_IV). Jurnal Ners, 14(2), 187 192. doi:http://dx.doi.org/10.20473/jn.v14i2.10873

\section{INTRODUCTION}

Technological advancement dominates global health care, transcribing and advancing nursing as an independent practice in human health care (Biswas, S., Kongsuwan, W., \& Matchim, 2016). Technology plays an important role in health care and it helps the nurses to provide comprehensive nursing care to the patients. Another study explains that in order to sustain the life of the patient, the nurses need to use machine technology (Biswas, S., Kongsuwan, W., \& Matchim, 2016). Furthermore, nurses are required to know and use this technology in order to provide nursing care. The TCCNI_IV has undergone a crosscultural adaptation study with 6 steps. The process adapted by the study is based on the translation, adaptation, and validation of the instruments or scales for cross-cultural health care in the research of Sousa and Rojjanasrirat (Sousa \& Rojjanasrirat, 2011). In this research, the researcher would like to examine the validity test and reliability test of TCCNI_IV. The experts evaluated the TCCNI-IV using a rating scale: 1 = not relevant, 2 = unable to assess or in need of so much revision that it would no longer be 
relevant, 3 = quite relevant and $4=$ highly relevant. From these ratings, the item (I-CVI) and scale (S-CVI) statistics were calculated. I-CVI represents the "proportion of content experts giving each item a relevance rating of 3 or 4," whereas S-CVI is strictly delimited by universal agreement (UA) This reflects the "proportion of items on a scale that achieves a relevance rating of 3 or 4 by all the experts"(Denise F. Polit, 2008). The reliability test was examined through the internal consistency and stability test. TCCNI-IV was administered to 135 nurses for the purpose of determining the internal reliability.

The ability of nurses in terms of using technology has become necessity because with this ability, the nurses can improve the quality of their nursing care. Technology as a part of caring in nursing has been introduced in several theories, such as the theory developed by Locsin (2005) in "The middle-range theory of technological competency as an expression of caring in Nursing". In Indonesia, technology has also been growing rapidly in health care and in all units of the hospital setting. The use of technology such as medical devices has increased rapidly and there is no tool that has been developed to assess the technological competency of caring in nursing. Locsin (1999) developed the technological competency as caring in nursing instrument (TCCNI) and this instrument was revised by Andrew Parcel (Parcells, \& Locsin, 2011).

The TCCNI instrument originally contained 30 items (Locsin, 1999). The instrument was modified based on written theory expert feedback and expert suggestions related to the clinical utility with associate and baccalaureate-prepared nurses in future investigations. Therefore, the final instrument version with 25 items had an S-CVI/UA of .72 (Parcells, \& Locsin, 2011). Furthermore, the crosscultural adaptation of TCCNI into the Indonesian Version (TCCNI_IV) was conducted by using the process recommended by Sousa \& Rojjanasrirat (2011). The process is described in 6 steps. First, there is the forward translation. Step 2 is the comparison of the two translated versions of the instrument (TL1 and TL2) in synthesis I. Step 3 is the back translation. Step 4 is the comparison of the two back-translated versions of the instrument (B-TL1 and B-TL2), namely synthesis II. Step 5 is where the preliminary psychometric evaluation of the scale will be done with a monolingual sample. Step 6 is the last step used to establish the initial full psychometric properties of the newly translated, adapted and crossvalidated instrument with a sample of the target population of interest.

In Indonesia, technology has also been growing rapidly in the health care sector and in all units of the hospital setting. The use of technology such as medical devices has increased rapidly. Therefore, the researcher wants to examine the content validity and reliability of the Technological Competency as Caring in Nursing Instrument Indonesian Version (TCCNI_IV) to see if the TCCNI-IV can be used in
Indonesia. This study aims to examine the content validity and reliability of the TCCNI_IV.

\section{MATERIALS AND METHODS}

\section{Research Design}

An exploratory sequential mixed method research design was used in this study. The researcher combined the qualitative method and the quantitative method, in order to gain comprehensive, valid, reliable, and objective data. The researcher used closed-ended question put to five (5) experts and to ask them to evaluate the TCCNI_IV using a rating scale: 1 = not relevant, 2 = unable to assess or in need of so much revision that it would no longer be relevant, 3 = quite relevant and $4=$ highly relevant. There are twenty-five (25) items consist in the TCCNI_IV.

The reliability test of TCCNI-Iv was measured using the internal consistency and stability test. The Technological Competency as a Caring in Nursing Instrument Indonesian version (TCCNI-Iv) was administered to 135 nurses for the purpose of finding the internal reliability. The measurement scales of TCCNI used a Likert scale with 5 categories ranging from 1- Novice to 5- Expert. The total score of each category ranged from 25 to 125 . Each range was categorized according to Benner's level of Competency (Benner's Stages of Clinical Competence Stage 1 : Novice Stage 2 : Advanced Beginner Stage 3 : Competent Stage 4 : Proficient Stage 5 : The Expert, 2011).

\section{Participants of the Study}

The participants of the study comprised of 5 nurse experts who participated in the qualitative study. One of them was a Doctor of Nursing, while the other experts had a Master's degree in nursing science and were the Chief Nurse of the hospitals. Based on a finite population of 208 nurses, a total of 135 nurses participated in the quantitative study. The selection of the participants was done through simple random sampling. The inclusion criteria consisted of nurses from the nursing ward of the hospital with experience totaling at least 1 year in nursing practice. The exclusion criteria consisted of pediatric department' nurses. The participants were recruited from two private hospitals in Surabaya.

\section{Research Instruments}

The original questionnaire is from the revised item TCCNI which contained of 25 items. The TCCNI_IV with a Likert scale ranging from Novice to Expert used to measure the responses of the participants for each item.

\section{Data Collection Procedure}

Prior to this study, approval of the research ethics committee of St. Vincent de Paul was obtained. After approval, the researcher worked on the recommendations. Permission from the directors and administrators of the hospitals was gained to conduct the study, and so the packet containing the letter from the ethics committee, the questionnaire, and the 
informed consent was presented to the nurse coordinator in the nursing wards of the hospitals. The participants who met the inclusion criteria were informed of the purpose of the study, its benefits, and finally, informed consent from the participants was obtained. Furthermore, no force or harm followed when and if the participants decided to withdraw their participation from the research out of respect to their human dignity and rights. The researcher also informed the participants that there will be no direct benefit regarding their participation in this study. The data collection was done in August 2018.

\section{Data Analysis}

A sequential mixed method analysis was undertaken to analyze the data. The researcher analyzed the qualitative data over the quantitative data. The expert panel was asked to evaluated each item of the instrument for content equivalence (content-related validity) using the following scale: 1-not relevant, $2=$ unable to assess relevance, $3=$ relevant but needs minor alteration and $4=$ very relevant and succinct. Items classified as 1 (not relevant) or 2 (unable to assess relevance) have to revised and the panel's experts were asked to provide suggestions. From these ratings, the item (I-CVI), scale (S-CVI) and Kappa coefficient of the agreement statistics were calculated. The quantitative data were analyzed using the Statistical Package for the Social Sciences (SPSS) version 24. The reliability was determined using Cronbach's alpha. The data was gathered from the sample of 135 nurses. The Likert scale used 5 categories ranging from 1 - Novice to 5 - Expert. The total score of each category ranged from 25 to 125 .

\section{RESULTS}

The results of the study have been divided into two parts: qualitative and quantitative.

\section{The Qualitative Part}

The results of the study in the qualitative part consist of the item content validity (I-CVI) and scale content validity (S-CVI) of TCCNI_IV. Table 1 shows that there were 20 items with an I-CVI 1.00 (Items no: 1, 3, 4, 5, $6,7,8,9,10,11,12,13,14,17,19,20,23,24$ and item no.25). There were 4 items with I-CVI 0.80: item no: 2 (Technology helps the nurses to know the "who" and "what" of each person), 16 (Nurses need to assess the patient regarding his or her knowledge to him or herself and the care that he or she received), 18 (Competent nurses do follow up his or her tasks and emotions creatively when meeting patient needs) and item no: 21 (Concern in the nursing process can happen in a learning and teaching situation between the nurse, patient and family member).

There was 1 item (item No.15) with an I-CVI 0.60 (Nurses need to train his or her caring perspective when assessing and interpreting the health service data). The result also shows that the S-CVI of TCCNI_IV is 0.936 .

\section{The Quantitative Part}

The results of the study in this quantitative part consist of the reliability test of TCCNI_IV. This was measured using internal consistency and a stability test. Table 2 shows that the Cronbach's alpha of Technological Competency in the Caring in Nursing Instrument Indonesian Versus TCCNI_IV is .980.

\section{DISCUSSION}

\section{Qualitative Part}

The researcher computed two types of CVIs, namely the content validity of individual items (I-CVI) and the content validity of the overall scale (S-CVI). For the first type of CVIs is the I-CVI. There was considerable agreement about how to compute the item-level CVI. The Content Validity Index (CVI) illustrates the degree of agreement between the expert raters (Andreou, Papastavrou, Lemonidou, Mattheou, \& Merkouris, 2015). This study shows that TCCNI-IV has an adequate and representative content validity (I-CVI) for all items. The criteria for item acceptability should be 1.00 when there are five or fewer judges. However, Lynn recommended that the I-CVI's criteria should be no lower than .78. (Denise F. Polit, 2008). Therefore, the I-CVI of TCCNI_IV in this study provides the information to guide the researcher for the next study focused on revising, deleting and substituting items, specifically items with an I-CVI less than 1.00 .

Most of the items of the TCCNI_IV have an I-CVI 1.00. This means that the items are adequate and representative of all items. This feasibly refers to the content validity of the technological competency. The caring in nursing instrument Indonesian Version (TCCNI_IV) was examined by experts and it additionally underwent the cross-cultural translation process. Moreover, TCCNI was investigated by theory and practice experts until the instruments consisted of 25 statements that originally consisted of 30 items. The item statements were revised or eliminated based on the quantitative content validity indices and specific expert feedback (Parcells, \& Locsin, 2011). Furthermore, the content validity of TCCNI_IV confirms that the items in the questionnaires are acceptable and understandable among nurses. Several factors could influence the understanding of the nurses related to each item in the questionnaire such as the nurse playing a major role in the use of technology in the health field and in daily care (Cargnin, Ottobelli, Barlem, 2016). The nurse's use the information technology tools is frequent in their practice (Barbara, Victoria, \& Carol, 2003). Critical to this nursing practice is the understanding of the meaning of the experience of a living human while being cared for and dependent on technologies for the purpose of human care (Koszalinski, \& Locsin, 2015). The limitation of this study is that the I-CVI questionnaire is less than 1.00 and it was not further analyzed. 
Table 1: The Content Validity Index (I-CVI) and Scale Content Validity Index (S-CVI) of TCCNI_IV

$\begin{array}{llc}\text { No } & \text { Items } & \text { Expert Panel total item } \\ & & \text { agreement }\end{array}$

agreement

$\begin{array}{lllll}1 & 2 & 3 & 4 & 5\end{array}$

$1 \quad$ Nursing as an important part of the
health service which focuses on human service

2 Technology helps the nurses to know the "who" and "what" of each person.

3 The final destinations of the nursing activity is healing, saving lives and increasing independence

$4 \quad$ Nurses use unique ways to serve their patients

$5 \quad$ Caring attitude is an interesting thing because there is mercy, physical attendance, a sense of comfort and personal appreciation

6 Technology and a caring attitude help to encourage self-esteem when it is used appropriately

7 To know what and who the patient is can mean there is an appreciation of the patient and not only his or her physical performance.

8 Nursing is a unique area of knowledge, skill and the ability to care

9 A caring attitude in nursing means there is a will to listen, to cooperate and to stay beside the patient

10 Nurses need to balance the dependency on technology usage and their ability to take care of the patient

11 Taking care means knowing the physical and emotional condition of the patient while handling them.

12 Nurses should involve the patient when arranging the nursing plan to guarantee the accuracy and completeness of the patient caring process

13 An ability in using technology is a skill to use machines in caring the patient

14 Nurses should honor the hope and dreams of every patient although it may change every time

15 Nurses need to train his or her caring perspective when assessing and interpreting the health service data

16 Nurses need to assess the patient regarding his or her knowledge of him or herself and the care he or she has received

17 Nurses should build a relationship with his or her patient when creating a safe and comfortable situation

18 Competent nurses follow up his or her task and emotions creatively when meeting patient needs

19 To understand the patient means to honor the patient as an individual every time

20 Competent nurses can anticipate patient needs and respect the patient's trust system at once. It is focused on the patient healing process 
Table 1: The Content Validity Index (I-CVI) and Scale Content Validity Index (S-CVI) of TCCNI_IV

\begin{tabular}{|c|c|c|c|c|c|c|c|c|}
\hline \multirow[t]{2}{*}{ No } & \multirow[t]{2}{*}{ Items } & \multicolumn{3}{|c|}{ Expert Panel } & \multicolumn{4}{|c|}{ total item } \\
\hline & & 1 & 2 & 3 & 4 & 5 & & CVI \\
\hline 21 & $\begin{array}{l}\text { Concern in the nursing process can } \\
\text { happen in a learning and teaching } \\
\text { situation between the nurse, patient and } \\
\text { family member }\end{array}$ & 3 & 3 & 2 & 4 & 4 & 4 & 0.80 \\
\hline 22 & $\begin{array}{l}\text { Concern in caring may reduce the anxiety } \\
\text { in the nurse-patient relationship }\end{array}$ & 4 & 4 & 4 & 4 & 4 & 5 & 1.00 \\
\hline 23 & $\begin{array}{l}\text { A sincere commitment to the patient's } \\
\text { needs, hope and dreams is a kind of } \\
\text { concern. }\end{array}$ & 3 & 4 & 3 & 4 & 4 & 5 & 1.00 \\
\hline 24 & $\begin{array}{l}\text { As a nursing concern, the ability to use } \\
\text { technology in many ways is to know and } \\
\text { understand one another, between patient } \\
\text { and nurse }\end{array}$ & 2 & 3 & 4 & 3 & 3 & 4 & 1.00 \\
\hline 25 & $\begin{array}{l}\text { Nurses use technology and human touch } \\
\text { together when building relationships } \\
\text { completely, focusing their concern }\end{array}$ & 4 & 4 & 4 & 4 & 4 & 5 & 1.00 \\
\hline & Total agreement & 0.88 & 0.96 & 0.84 & 1 & 1 & S-CVI & 0.936 \\
\hline
\end{tabular}

Table 2. The Reliability Test of the Technological Competency of the Caring in Nursing Instrument Indonesian Versus (TCCNI_IV).

\section{Reliability Statistics}

Cronbach's Alpha $\mathrm{N}$ of Items

item is unable to assess the relevance (item no.15: ICVI 0.60), this is most probably because in reality, the nurses' caring perspective when assessing and interpreting health service data is a fundamental practice conducted by all nurses. Therefore, the nurses do not need to train his or her caring perspective when assessing and interpreting the health service data. The nurses acknowledge that caring is at the core of the nursing profession. Selfawareness helps to improve the nurses' caring behavior and understanding of themselves in respect to their own values and beliefs in order to understand the client's perspectives (Biswas, S., Kongsuwan, W., \& Matchim, 2016).

The second type of CVIs is scale content validity (S-CVI). The S-CVI is defined as the proportion of items given a rating of 1 - not relevant and 2 - unable to assess the relevance by the experts involved. The items were given a rating of 3 - relevant but needs minor alteration and 4 - very relevant quite/very relevant by the experts involved. According to many writers, the S-CVI's acceptable level is .80 or higher (Denise F. Polit, 2008). In this study, the S-CVI of TCCNI_IV is 0.93 , which means that the items are adequate and representative for all items in order to measure the construct of interest. The use of technology plays a significant role in the nursing service. The nurses will be able understand their patients as a whole through the help of technology.
Thus the nurses require an enormous amount of technical skills, effort and competency when managing technologies harmoniously with the intention being to result in positive human health perspectives.

\section{Quantitative Part}

The quantitative part consisted of the reliability test of TCCNI_IV. It was measured using internal consistency and a stability test. Cronbach's alpha was the measure used to determine the reliability (internal consistency) of the items in the questionnaire. The range from 0.70 and 0.95 is an acceptable value for Cronbach's alpha (Beck \& Gable, 2001). Another researcher used the internal consistency to refer to the interrelatedness of the items. They distinguished internal consistency from homogeneity by claiming that homogeneity refers to the uni-dimensionality of a set of test items (Tang, Cui, \& Psychology, 2009).

In this study, the results show that the Cronbach's alpha of TCCNI_IV is .980, representing a good value (Al Hadid, Abu Hasheesh, \& Al Momani, 2011). This result means that the questionnaire is considered to have high reliability. This is most probably because each item has been examined by experts before being administered to the participants. Furthermore, the TCCNI_IV underwent both development and psychometric testing. 


\section{CONCLUSION}

The technological competency of the caring in nursing instrument Indonesian version (TCCNI_IV) is found to be both valid and reliable. It is recommended that the developed instrument is further tested for its reliability and validity in a larger setting. It is also recommended that the questionnaire can be used in a nursing ward hospital with nursing students as the sample.

\section{REFERENCES}

Al Hadid, L. A., Abu Hasheesh, M., \& Al Momani, M. (2011). Validating a tool that explores factors influencing the adoption of principles of evidence-based practice. Journal of Nursing Education, 50(12), 681-687. https://doi.org/10.3928/0148483420110930-03

Andreou, C., Papastavrou, E., Lemonidou, C., Mattheou, K., \& Merkouris, A. (2015). Adaptation and Validation of the Learning Style Inventory Version 3.1 in Greek Language: A Methodological Study. Journal of Nursing Measurement, 23(2), 88E - 111. https://doi.org/10.1891/1061-3749.23.2.E88

Barbara, J., Victoria, L., \& Carol, J. (2003). Nursing information technology knowledge, skills, and preparation of ...

Beck, C. T., \& Gable, R. K. (2001). Ensuring content validity: An illustration of the process. Journal of Nursing Measurement, 9(2), 201-215.

Benner' $s$ Stages of Clinical Competence Stage 1: Novice Stage 2: Advanced Beginner Stage 3: Competent Stage 4: Proficient Stage 5: The Expert. (2011). (1984), 2011.

Biswas, S., Kongsuwan, W., \& Matchim, Y. (2016).
Technological Competency as Caring in Nursing as Perceived by ICU Nurses in Bangladesh and Its Related Factors. Songklanagarind Journal of Nursing , 36(1), 1-20.

Cargnin, Ottobelli, Barlem, C.-V. (2016). Technology in Nursing care and Workload in an ICU. J Nurs UFPE on Line., Recife, 10(Suppl. 2):903-7.

Denise F. Polit, C. T. B. (2008). The Content Validity Index: Are You Sure You Know What's Being Reported? Critique and Recommendations. Research in Nursing \& Health, 31(4), 341-354. https://doi.org/10.1002/nur

Koszalinski, R. S., \& Locsin, R. C. (2015). Persons who Dependent Upon Technologies for Care: Lived Experience of Being Cared for Following Lower Limb Amputation. International Journal of Human Caring, 19(4), 38-43. https://doi.org/10.20467/1091-5710.19.4.38

Locsin, R. C. (1999). Development of an instrument to measure technological caring in nursing. Nursing \& Health Sciences, 1, 27-34.

Parcells, D. A., \& Locsin, R. C. (2011). Development and Psychometric Testing of the Technological Competency as caring in Nursing Instrument. International Journal of Human Caring, 15(4), 813. https://doi.org/10.20467/10915710.15 .4 .8

Sousa, V. D., \& Rojjanasrirat, W. (2011). Translation, adaptation and validation of instruments or scales for use in cross-cultural health care research: A clear and user-friendly guideline. Journal of Evaluation in Clinical Practice, 17(2), 268-274. https://doi.org/10.1111/j.13652753.2010.01434.X

Tang, W., Cui, Y., \& Psychology, E. (2009). Internal Consistency: Do We Really Know What It Is and How to Assess it ? 2(2), 1-16. 